\title{
Strategic Essentialism and Ethnification
}

\author{
Hand in Glove?
}

\author{
Elisabeth Eide
}

\begin{abstract}
The present article sets out to explore certain aspects of how individuals with an ethnic minority background experience the journalistic media. It is derived from a project based on in-depth interviews aimed at mapping the media experiences and strategies of individuals with a minority background. Many tell of their experiences of being ethnified or subject to culturalization by the reporters - and thereby ascribed a lesser Norwegian identity even if they happen to be born and raised in Norway. In several cases, the interviewees demonstrate how they have had to emphasize their ethnicity in order to gain better access to media with regard to issues and causes that have nothing to do with their minority background. These continuing intersecting processes may inspire (strategic) essentialism among minority groups as a necessary albeit disputed way of obtaining media attention and recognition. Anthropologists' approaches to essentialism, ethnification and culturalization are discussed, and by way of conclusion, the article discusses Gayatri Spivak's "strategic essentialism", its advantages, pitfalls and limitations. ${ }^{1}$
\end{abstract}

Keywords: culturalization, ethnification, minority, media representation, strategic essentialism

\section{Introduction}

In a society where you define a group, and from a position of power you speak of this group, then the group must be allowed to have their voice heard. Indirectly you force this voice to come forward. (Marian)

I'll name myself. (Haddy N'Jie)

At times, encounters between journalists and their sources may seem like clashes between representatives of different communities of interpretation. While reporters tend to focus on what differentiates certain minority persons from the majority mainstream and to assert their group belonging (Eide 2002, Eide \& Simonsen 2007), their sources may wish to be treated as individual citizens, not as "special species". But belonging to a (perceived) minority may also entail an advantage related to the fact that the background of minority persons is more complex than that of the average reporter. This may be seen as a transnational corrective to a media representation that is oftentimes influenced by "restricted prisms" (Curran 2005), and as part of the social capital required to assert group rights. 
Storm-Mathisen and Helle-Valle, in a discussion of identity, argue that "the term 'identity' not only has academic but also commonsense denotations in directions of an essential and non-situated 'picture' of persons, that they define themselves in opposition to" (2008: 59). The present project tries to capture both this opposition and a variety of pragmatic adjustments to Norwegian media made by informants with considerable media experience.

The methodology includes mapping the media exposure of our interviewees and conducting in-depth interviews. Eighteen persons with an ethnic minority background have been interviewed ${ }^{2}$. The informants share some characteristics: They have all received considerable exposure in the Norwegian media. And to a greater or a lesser degree, they are 'visible' minorities in the sense that they are routinely asked by mainstream Norwegians, "Where do you come from?" Their or their parents' origin is either Asia or Africa, and a majority, but not all, are Muslims. About half were born and raised in Norway, and ten are women.

\section{Being Norwegian}

All categories have their flaws. For the purpose of the present article, the informants are called individuals/persons "with an ethnic minority background" or abbreviated "(of) minority", while the perceived majority are called "ethnic Norwegians" or "(of) majority", as opposed to "Norwegians", which is how many people who were born in Norway or who have Norwegian citizenship define themselves. The latter category does not group people according to ethnic or racial criteria. These different notions imply recognition that Norway is a society in which Norwegian-ness is still largely associated with the social category of "whiteness", that is, with race and colour. Furthermore, being Norwegian, Muslim and brown is often not seen as one of the several valid ways of constituting a Norwegian identity. On the other hand:

Whiteness is not a monolithic discourse, and whites are not a cohesive, homogeneous ethnic group. [...] The fact that whiteness is constantly threatened by its own heterogeneity and hybridity reveals it for what it is: an intrinsically pathological discourse which has been constructed to create the fiction of a unitary and homogeneous culture and people (that is, essentialist). (Gabriel 2000, p. 68)

As both a researcher and citizen, I would adhere to a non-colour, non-racial and nonculturalized way of defining the condition of being Norwegian, in which citizenship and individual sense of belonging play dominant roles. This is oppositional to a 'roots' definition of identities, which may be read as more hierarchical (homeland over 'new' land) and static. Storm-Mathisen and Helle-Valle suggest that in many analyses

[...] using 'diaspora' might be more fruitful than using the term 'ethnicity'. While the latter almost by necessity points toward a group or category of people with (assumed) common traits [...] 'diaspora' focuses on the practical situations certain people are in. The term points to how people are conceptually and practical rooted in two different countries/places but without implying anything about their belonging to a specific ethnic group. (2008, p. 56) 
The argument is valid, but the term 'diaspora' may also be interpreted in ways associated with group belonging and the possession of common traits, among them a shared longing for the past/lost homeland.

This article relates critically to essentialism and ethnification, and thus I hope to avoid the pitfalls of assuming such traits. Rather, my aim is to demonstrate the diversity of experiences of and approaches to media found among people who have a reflexive attitude towards media representation.

\section{The Journalistic Gaze}

Our interviewees often feel that they are portrayed in narrow, stereotypical ways that exclude many layers of their experience. In Bourdieu's terms (1999), the journalistic "gaze", which is linked to journalistic conventions and individual experiences of the journalist, works as a filter. This selectiveness is often accompanied by negotiations (both before and during a media interview) between a journalist from the majority mainstream media (at times also the minority media) and the minority actor. Even if the actors experience that they are at least being rendered visible and have been invited to express themselves, they realize that they often have to struggle - and make compromises - to be fairly represented. This includes both a validation of their quotes and a discussion on what is "important" for a media story. The actors demonstrate a multitude of media strategies based on their experiences and routines, some of which lead to exclusion of certain media and media formats or non-co-operation with individual journalists. While many of these experiences are not unique to minority actors, some of the negotiations are related to specific experiences of ethnification (see below).

I understand that the informants' stories are their own version of events, and because some of their experiences are long-gone history, their memories may be unreliable. The reporters they have met may have other versions of the encounters. On the other hand, when several voices repeat some of the same elements, tentative conclusions may be drawn suggesting that these are important media experiences informed by resourceful persons tracing their background to (more or less) vulnerable minority groups.

\section{Ethnification and Essentialism}

Marianne Gullestad, who has done extensive anthropological research in Norwegian society, suggests that the ethnification of discourses has increased from around the turn of the millennium, making it harder for immigrants to belong in this society. She also feels that what might create a less tense situation would be a stronger emphasis on citizenship and a lesser emphasis on nationality or ethnicity, as the latter often excludes people born elsewhere (or with parents born abroad).

Anthropologists have primarily referred to ethnicity rather than to 'race'. But [...] focusing on ethnicity frequently implies that 'race' unobtrusively slips in through the backdoor. And, I want to add, it usually implies that social class and gender slip out through another backdoor. (Gullestad 2001, p. 47, my translation ${ }^{3}$ )

Gullestad is concerned with anthropologists' emphasis on problematizing ethnicity, as the characteristic that tends to divide the 'us' and the 'them', instead of focusing 
on other socially constructed characteristics of the individuals and groups in question. The same tendency may be observed in media representation (Eide \& Simonsen 2007, Fjeldstad \& Lindstad 2006).

One might consider that, following her view, studying the media representation of people with an ethnic minority background is somewhat counterproductive, as by doing so one inevitably adheres to certain unexamined selection criteria. But by critically applying an inclusion/exclusion perspective, one may be able to register to which extent the construction of otherness is foregrounded or subordinated to a more universalistic (we as gender, class or Norwegians) perspective.

For the purpose of media and journalism studies, ethnification may be defined as a one-sided, dominant media focus on a person or group as an ethnic other, an emphasis on her difference (from a presumed 'us'), based on her being (more or less) visibly different or on a tacitly presumed background that differs from the mainstream. This media ethnification may take the form of conflict if it identifies the actions of that person or group as narrowly determined by their "roots" as members of the minority "other". This often goes hand in hand with presupposed binary oppositions between a majority us versus a minority them; and subsequently, the factors that unite the populace and the processes of syncretism and universalism as well as the fluid characteristics of identities are ignored.

Ethnification is not a product of increased migration. Rather, as Friedman sees it, "migration has become ethnified in a period in which assimilation and weaker forms of integration have failed" (Friedman 1998, p. 239). Moreover, ethnification does not differ radically from essentialism. Friedman writes that while ethnification does not necessarily entail exclusion, it can be "segmentary and inclusive"; it may also be "essentialist and exclusive, the practice of identification and differentiation can lead to violent outcomes. In fact, it is logical for essentialization to accompany ethnification no matter what the social and cultural conditions" (ibid.).

\section{A Contested Idea}

Essentialism presupposes that a group or a category of objects/people share some defining features exclusive to the members of this particular group or category. This has been a highly contested idea throughout the social sciences and particularly in post-colonial as well as colonial discourse studies. Essentialism is often discussed together with the questioning of categories like race and nation. On the other hand, at a more pragmatic level, essentialist practices and modes of representation have been applied by groups and individuals in the promotion of certain minority rights or demands (as well as liberation struggles), as may also be seen in the empirical study on which the present article is based. Sometimes this is a conscious albeit partial appropriation of an essentialism imposed by others (the elite, the powerful) on the part of a group wanting to achieve certain goals. The group thus tries to define itself by its own criteria, but at times essentialist hegemonic representation is internalised, as Sartre (1963) finds with the Jewish experience.

But oftentimes practices may differ substantially from essentialism as a certain type of hierarchical, authoritarian othering and its internalization by the oppressed group. Essentializing the self may be part of a negotiated half-way adaptation to the rules of the game set by, for example, mainstream media, as seen in some of the examples below. 


\section{I say $\mathbf{I}, \mathbf{I}, \mathbf{I} \ldots$}

Essentialism entails that a specific entity contains a set of characteristics common to all entities of that kind. Several of our Muslim interviewees have experienced an ascribed "collective responsibility" of sorts. By virtue of their adherence to Islam, they are frequently confronted with fundamentalism or acts of terrorism, and are subsequently asked to condemn them.

I just try to show the whole spectrum, to highlight more nuances, since in the media the image may easily be very one-sided [...] I got the message that since you are against terrorism and Islamism you must come forward and distance yourself from it. [...] I am guilty just because I am a Muslim. [...] Of the same person I was accused [...] of being co-responsible for discrimination of Muslim girls since I wear hijab. $\left(\mathrm{Cecilia}^{4}\right)$

This interviewee feels she needs to "answer for" the scepticism and the misgivings found in society with regard to Islam, although she emphasizes that she does not want to become a spokesperson. "Therefore I say I, I, I all the time, because I cannot speak on behalf of everyone" (Cecilia).

Cecilia emphasizes individual needs - and various streams of journalistic representation. Once one is labelled a spokesperson - or a group-attached individual - some of one's own individuality inevitably is "backgrounded" (Fairclough 1995, p.106). On the other hand, the objections she raises may also be seen as an expression on behalf of a (silent) majority (Muslim girls observing hijab) within a minority (i.e., a group of sorts) whose members do not want to be essentialized.

\section{Selling a Story}

Another informant had been elected leader of an organization (having nothing to do with ethnicity, minority or religion) and wanted attention from the press to publicize a certain political initiative. He received no response. On his third attempt, he (Hamid) "sold the case" as a story from the angle of him being the first such leader from an ethnic minority background. The story was then accepted and aired. In the end, he was satisfied with the result, as he was also allowed to speak on the topic he had raised in the first place. He says he feels it is easier to sell stories of common interest - regardless of the topic - if he focuses on his status as "being a minority".

Aamir feels that we (i.e., the Norwegian society) "have a debate marked by myths [...] a debate marked by the fact that nobody wants to see through these myths [...] There is no room for that." Furthermore, commenting on the media polarization of the "immigrant debate", he adds flatly "if you have an initiative aimed at reconciliation, just forget it." Although he is a professional, he says that only once during the past ten years has he been invited into a [media] debate that did not have to do with "immigration or integration".

When you write about immigration and integration, you'll be published immediately. When you write about something Norwegian, or let us say something that does not have to do with immigration and integration, it will be somebody else. Then you belong to a different league. (Aamir) 
According to Aamir, it is hard to find a space for him to express himself as an ordinary citizen not associated with his minority position. Aishya also experienced being framed as a minority when she attained a leading position in the public sphere in Norway:

I must say that when I started [...] as a Norwegian-Pakistani, born and raised in Oslo, having gone to a Norwegian school and with all my education from the Norwegian [...] educational system, and Norwegian friends and feeling rather Norwegian suddenly I enter a situation as a immigrant [representative] and then I thought ... it made me react rather strongly. (Aishya)

She wanted to represent her mainstream organization, not "immigration" and raised the issue with all journalists who wrote or spoke of her first and foremost as an "immigrant". She finds it easier to achieve media attention "when it is a case related to minorities [...] than a case that has to do with the entire population".

When asked whether he has sometimes been interviewed by journalists about something universal - cases unrelated to his minority background - Babur answers hesitantly:

Not much. By random I was asked about the European Union, they have asked me about my opinion of the King's family; should we keep them. I have no ambition of becoming a king [laughs] so it's all right with me. Another example is the $\mathrm{KRL}^{5}$, which has to do with everybody, but there one is asked to comment from one's own side. (Babur)

Here, "one's own side" refers to the fact that Babur was invited to speak from his position as a member of a religious community. On the other hand, he does not mind that too much, having experienced a position of religious leadership. This indicates that the degree to which people feel essentialized may have a great deal to do with what position they prefer to take in society: representing an ethnic or religious minority as part of their career or engaging in the public sphere as citizens more generally.

\section{Fixed Stories}

Jalil says he feels the stories are often fixed before some interviews take place; the journalists are looking for difference and sensation, especially when it comes to the Norwegian-Pakistanis.

This holds for very many cases. [...] right now it has to do with Islam and Muslims. It's not immigrants, it's not the colour of your skin any longer, it's not the smell of garlic, but now it's religion, religious questions, Islam and fanaticism, nationalism and all that, and that's because one doesn't want to go in-depth, but instead to sell. (Jalil)

Jalil's experiences are not unique to minorities (and he recognizes this), because the general journalistic conventions tend to concentrate on the unusual, the different and deviant, the confrontational, the extremes, the conflicts - and with increasing commercialization as well as greater focus on the private sphere ${ }^{6}$. The special focus people with a minority background experience - for example when misconduct is explained as rooted in "culture" - differs from the way in which abuse is mostly seen as individual cases of deviance in majority circles. 


\section{Culturalization}

Jalil highlights a variety of essentializations. The concentrated focus on religion, though, may be considered as culturalization ${ }^{7}$, a process which may be said to replace a more outright racial discrimination. The attempts by certain media to make all adherents of the Muslim faith accountable for the deeds of some very extreme Muslims, as indicated above, point in the same direction. Stolcke writes about a "new form of exclusion rhetoric in the west which is based on a homogeneous, static, coherent and rooted notion of culture". Stolcke applies this concept, as she emphasizes that the rhetoric does not necessarily imply a ranking of practices and thus can not be labelled as racism. (in Gullestad 2002, p. 150) ${ }^{8}$

According to Gullestad, culturalization concerns:

the concept of "culture" being imbued with political ammunition, but simultaneously to a degree being situated above politics. [...] 'Culture' has become a 'language' which is applied to interpret social differentiation and inequality, and thus contributes to conceal the underlying structural contradictions and hierarchies. Most people (including researchers) shift without reflexivity between different concepts of culture - mainly either an essentialized and objectivating concept, or a processual and elastic concept. But in debates on "immigration", often the objectivating concept rules. (ibid. pp. 57-58)

Gullestad underlines the need for elastic concepts. She also addresses the concern of researchers who risk (like she does in her book) "sustaining and reproducing the binary I want to problematize in its adversary. For this reason, I again underline that 'majority' in this investigation primarily is a frame of interpretation which all in one way or another live in and relates to" (ibid. 58-59). Similarly in our study, the interviewees address the mainstream majority media and their reporters as their representatives.

Culturalization is an ambiguous concept, as its opposite (de-culturalization) has historically meant the deprivation and forced assimilation of indigenous peoples and migrants. In the context of the present project, its meaning occurs for example when individuals or groups with a minority background are working with their identities in processes of transition, but are not seen as doing so.

\section{Multiculturalism - a Doomed Practice?}

The debate on multiculturalism is related to the experiences of ethnification, essentialism and culturalization. British historian Kenan Malik has been central to this debate, ever since his publication of "The Meaning of Race" (1996). Malik criticizes multiculturalism as policy and strategy, because an emphasis on or celebration of difference is problematic as a strategy of the oppressed. His main argument against this strategy is that the people in power, people who are in a position to discriminate, or who want to discriminate, can easily do so to marginalize the Other. To him, multiculturalism is the product of political defeat and the abandonment of progressive change and equality (Malik 2002).

But how to define celebration of differences? Bushra has her own ways of asserting her identity:

[...] when I am characterized, I only correct [the journalists] if I have [been called] for example "the immigrant woman." You know. I don't like that one. I'm not 
... I have of course immigrated to Norway, but I'm no longer an immigrant. I'm part of the minority, a woman of the minority. I would really like to call myself a "black woman". But I've met with a lot of resistance. "But you're not black", you know. Black is applied to Africans. That Black could be a political concept has not occurred to the journalists. (Bushra)

Bushra expresses a wish to distance herself from the perceived cultural whiteness of the majority by counterpoising blackness. According to her, this self-defined blackness has nothing to do with ethnicity, but rather is primarily a political issue generated by being seen/treated as different. And far from celebration, it is a political assertion, a way of talking back against discriminating practices.

The celebration of similarities has its own inherent problems. Similarity can be a straitjacket forced upon vulnerable groups, cultures and even nations that feel they are in a defensive position and want to preserve and develop (parts of) their cultures (and hence their distinctiveness) in opposition or supplementary to another, dominant and oppressive culture. This may often be defined, as Gullestad expresses it, as critical preservation (2002). Vulnerable groups may both defend multiculturalism and resort to essentialism as a defence of their values and/or interests. But multiculturalism does not have to entail defence of isolationism or backward and oppressive practices, rather it may be a politics of recognition including struggle against social inequality.

\section{Representing or not Representing the World}

Often the reverse is the problem, not group-based essentialism or celebration of difference. Several of our informants state that they feel that they are culturally Norwegian, which also shows that they are tired of being ethnified within Norwegian culture and viewed through a culturalist lens in a specifically Norwegian way:

[...] my struggle then was to break down the prejudice against Muslim women in the Western world or primarily in Norway. I define myself as Norwegian first and foremost, but Muslim, and for me it's important to give a more complete picture of how Norwegian-Muslim women live. But it didn't turn out like I had thought, since I was asked about everything from legal practices in Saudi Arabia [...] I was made responsible for everything in the Muslim world. (Mona)

Mona expresses the need for Norwegian media to accept as normal the position of being Muslim and Norwegian, but feels she is again and again asked about issues in far away countries, be it Nigeria or Saudi-Arabia or the rest of the Muslim world, practices she is not familiar with, having been raised in Norway.

On the other hand, some interviewees feel that the expertise they have acquired from their diverse backgrounds is not thoroughly respected by some media, and that they are marginalized by ethnic Norwegians:

We sit here $[\ldots]$ with the $[\ldots]$ blood and ballast, but still, every time one is to watch our country ${ }^{9}$, and [someone] has comments or remarks on [...] it's always the ethnic white Norwegians who are to shed light on [...] since they have read books, but we, who are grassroots and resource persons, are almost never asked. (Javed) 
Several similar complaints have been registered. Most likely this has to do with a notion among journalists that persons who can trace their background to countries (temporarily) focused upon by media tend to be biased or involved in particular party politics. Another explanation may be the tacit social structure inherent in media production, in which the preferred spokespersons and commentators tend to belong to the "chattering classes", often people with a title and some academic or similar merit (see also Gans 1979).

In most of the informants' experiences there is a political element. And even if this has nothing to do with answering questions about politics and practices in distant countries, dilemmas in media representation may concern other practices with which most individuals have a hard time identifying:

[...] always when the media addressed me, it was more about minority girls, minority girls. I was more interested in the LO [equivalent to TUC] crisis $^{10}$, she was a leader, and a woman. Why didn't people ask me about this? [...] Why is it always like this when it comes to forced marriage or circumcision [...] then they come and ask what do you think about this? (Noor)

Noor says her experience is that she is only asked questions related to "being a minority". Earlier work on a "ladder of visibility" in journalistic interviews (Eide 2002) suggests that many competent sources are reduced to "cases" in which they are allowed to represent themselves as an illustrative example within a certain frame, but not to speak of other issues, in the present context issues related to Norwegian politics in general.

They [the journalists] sometimes consider [us] as a pool of immigrant women [...] in other words a store containing immigrant women. So from that store they can order what they wish, you know. [...] For example: "We are now working on a report on this and that group, so do you have someone ... We want to have contact with a woman who is so and so". [...] We receive many calls like that. (Bushra)

Bushra says that, in the beginning, her organization was rather annoyed with these calls, but after a while they have learned to answer nicely: "Unfortunately we don't have that kind of woman in store yet, so can you call back", or they insist that "If you want a competent statement on this issue, we will gladly provide one.” (Bushra)

Representing an organization, Bushra demonstrates her media competence by trying to negotiate for being treated as an expert and commentator, not as a pool providing victims. The background is that the informants largely find themselves trapped on a lower echelon in the hierarchy of sources - being reduced to "apt cases" demonstrating misery - while majority "experts" convey the more general and analytic picture also about minorities and their situation; i.e. the "on behalf of"-syndrome at work. (Eide 2002)

\section{Forced Marriage?}

Cecilia, when asked whether there are topics that she would not like to be interviewed about, responds the following:

Marriage. I think media people, now I say media people and am thus really prejudiced myself, but I think many journalists think that since you're a minority they can pose very private questions, and it is self-evident that you should answer. [...] I feel that with Muslim girls it is okay to talk about such issues, but with whom 
you should marry [...] I would not like to speak about this publicly, just because I am a Muslim. [...] Even if I am a Muslim, I have my limits just like everybody else. (Cecilia)

This intimization of individuals with a minority background ('tell about your family life, about marriage' etc.) in media representation often (as with individuals of majority, but often with different emphasis) implies a backgrounding of the issues they would like to highlight or be engaged in - a negation of the way in which they would like to be represented. It could also be seen as an operative framing called "possibly forcibly married", which in turn may inspire a "majority gaze" or yet another simple categorization of what is in fact a complex issue.

In one special incident Cecilia and her father disagreed. A journalist came to their home and asked (perhaps jokingly): "Well, have you thought of marrying away your daughter, and is your son forcibly married?"

I felt so uncomfortable and it did not correspond to the expectations I had, so I said, no, I don't want this any more. I will not tolerate this. [...] Yes, yes he [my father] did not see this as a problem. He was very positive. For he only thought that this is an option for $[\mathrm{him}]$ to say that all $[\ldots]^{11}$ parents do not marry away their daughters, but I remained very critical. Maybe because I had some media experience and was very critical [about it]. (Cecilia)

This difference of opinion between father and daughter requires a multitude of explanations. The daughter had more (negative) media experience than her father did. The father, lacking this experience to a degree, may have felt more respectful towards the media and their hierarchies, and thus he did not question the media delving into his private family life. Alternatively, he may be used to marginalization and being rendered invisible, and was thus happy to have a chance to express himself. Or are we witnessing a gendered difference here, with the daughter feeling more vulnerable faced with questions about her private life and family relations than her father does?

\section{Group Ambiguity}

As mentioned above, majority is not a fixed entity. But if it still corresponds to a frame of interpretation, then minority may also be such a frame with regard to which "one lives and relates". And our interviewees - having to live within both frames, as the majority frame is closely related to the hegemonic understanding of relations in a society - are inclined to develop a dual vision of sorts, which many people belonging to the majority may not possess because it has not been imposed upon their daily lives. During the interviews, several of the informants explicitly analyse the roles of the media practitioners from their majority position, simultaneously narrating their own specific experiences.

I must say, before I forget, [...] when one talks about responsibility and who has it and who will have to assume it, one often forgets to say what is positive. I must admit that, by and large, I have had very positive experiences and have been well received by Norwegian media also. [...] And when I think of it in hindsight, I think that I cannot take the liberty of directing others' opinions, since that is exactly what I do not want them to do to me. [...] They have their understanding and I 
have mine. [...] In hindsight I have learned to value even the foolish interviews, and maybe they have represented the seed to a discussion that has led to some prejudices being broken down. Because everybody reads and understands things differently. (Mona)

Although she has experienced being culturalized in interviews, and being confronted with essentialized Muslim practices around the world, this informant preserves her optimism and tries to see the world through the lenses used by mainstream journalists. She seems to understand their search for deviation, even though it entails an exclusionary and static view of sorts.

Despite being Norwegian by birth and citizenship, several informants find themselves in roles involving group membership or group identity, and have experienced struggling on behalf of this group - or at times on behalf of an entire community.

And then you have those [journalists] who come tip-toeing in and, like, are so determined about what it should be ... for example: "Yes, you say you don't want to be seen as a group, but you are a group and you talk about not wanting to be seen as so very different, but you talk about different-ness all the time." And these questions are also good, but she [the journalist] is also determined before she comes and when I say that it is all right for me to be able to say that I'm Norwegian ... but then she has already said that it's us who ask for this, and then we don't stand a chance because [...] it's closed from the beginning to the end, and then it turns out hopeless and bad. (Sonia)

This informant - as several others - speaks very critically about being framed journalistically. If you (sometimes) speak as or on behalf of a group, you are deemed to be that group. And in the minority context, which here constitutes part of the framing of an interview, you are different in special ways. Sonia's project in the public sphere has been linked much more to being seen as different than to being different. Thus, when she supposedly speaks "about different-ness all the time", it is probably because she is treated as different most of the time. Thus, the media person mentioned above seems to blame Sonia and her group for being Othered by the media (and by the hegemonic society) and for resisting this Othering. Another informant expresses more understanding of this ascribed 'double identity':

Personally I was very concerned - as a spokesperson - about defining myself as a Norwegian. Norway is my homeland, and the only country I know. I am very proud of being a Norwegian citizen and very concerned about the public debate, even outside the one on minorities. But naturally, since I'm a minority [person] this topic is also very important to me, as Norway otherwise is equally important. (Mona)

Mona's view corresponds to Gullestad's notion of "living in" and "relating to" a frame of interpretation. She is Norwegian (and thus relates to the majority frame), but she also senses her belonging to a minority and feels that is an important side of herself.

\section{A Period of Transition}

This in-between situation is now widely accepted - at least theoretically among researchers (Bhabha 1990, Maalouf 2000, Eriksen 2005, 2008). It seems unlikely that the media 
will collectively and rapidly follow suit, as a less fixed, often fluid in-between-ness fits more uneasily with the prevailing media doxa of focus on different-ness, extremes and polarization (Bourdieu 1999, Benson \& Neveu 2005). ${ }^{12}$ In spite of their struggling and negotiating with media conventions and their proponents, several informants express their hopes for the future, as they sense that we are living in a period of transition:

Therefore, I feel that we are in a period of transition. I don't fear this period [...] or the debate, but one feels very small and in an uncomfortable situation when you [i.e. the media] lean towards the negative, since this has consequences for me in my daily life and it has consequences for Muslims. Everything I say and everything I mean will either confirm or reject prejudice. (Mona)

The consequences may be rather specific, as when some individuals belonging to a certain minority group commit crimes. When it happens, says Jamaal,

... ethnic Norwegians rang me up and cursed me. I had several telephone threats, very many of them. [...] And I asked myself, should you defend them [the culprits] even though you know what they've done? You easily end up in a defensive position. Very often I try to get ethnic Norwegians or the majority [...] to do this, provide nuances, say that it's not like this, or that this is just a group [...] I try to make it so that there's no connection between being a $[\ldots]$ and a certain criminal behaviour. It's often a little difficult (Jamaal).

Jamaal's experience is that of being associated with the deeds of certain individuals, as he has functioned as a spokesperson of sorts for the minority group whose background is in the same nation. At times he finds it hard to be understood when he asks for nuances, but he follows a strategy of aligning himself with people of the majority - perhaps due to their presumed higher credibility in Norwegian society.

As human beings, we tend to classify and define others when defining ourselves. Often, this is practised with a slant of negation: I'm not her; we're not like they are. It may also involve saying - on behalf of a group - that we are not like this [criminal] individual, as with the above experience. When, owing to media representation, a criminal act is identified with a certain ethnic group, it may simultaneously imply a point of view of this having nothing to do with Norwegian-ness.

Self-definition does not have to be imbued with negativity, but when, as occurred in a recent debate in Norway, some majority sources said it was impossible for so-called second generation immigrants to be defined as Norwegian, then such self-definition of Norwegianness is negative. This exclusionary thinking is still widespread, and consequently, it may inspire an orientation towards presumed "roots". As Friedman writes:

The relation of categories of identification to the process of transnational structuring always harbours a degree of rooting. This is a complex variable of course and it depends very much on circumstances, cultural strategies, and the way that they change over time. Thus all the groups in question can root themselves more or less intensively. (Friedman 2005, p.149)

Furthermore, Friedman states that periods of ethnification may help root certain diasporic societies, and that the related essentialism may work in the same direction - rooting minorities more profoundly in a (spatially or imaginary) distant homeland. He thus il- 
lustrates the dialectics between lack of majority recognition and minority rooting outside of the country of residence.

\section{Fruitful Experiences}

Myra Georgiou underlines the need to undertake enquiries into identity that go beyond the essentialization of traditional studies of race and ethnicity:

Essentialisms, which consider ethnicity and Diaspora as being either bounded within inescapable dependence upon a distant homeland or doomed to fade out through inevitable assimilation, fail to grasp the negotiations, conflicts and unease of the diasporic condition in relation to both the country of origin and the country of settlement. (Georgiou 2006, p. 154)

The interviewees are living examples of this complexity, rejecting the "either-or" approach presupposed by essentialism. But there is no easy way of ridding oneself of essentialism, and - as Gullestad puts it - "instead, the question that needs to be raised constantly is what kind of essentialisms at any given moment is intellectually and politically fruitful" (Gullestad 2002: 134). Within a diasporic community there may be special issues of concern; for example, oppressive traditions that require spokespersons "from within" to speak for the (potential) victims:

I don't think it's much fun to talk about [my experiences] on TV or in the newspapers all the time. I do it because it I know this is what many people need. Their stories are not highlighted. If I have to use myself a thousand times, I'll do it so that their stories are told in the media and so that they will be taken seriously. (Soham)

Soham explicitly states that she represents herself in the media with regard to a group that is vulnerable to a threatening tradition, and thus posits herself as a spokesperson for those who are not capable of speaking of their own experiences. Thus, in the foreseeable future, she will often be associated with this mode of representation from the media. Her sense of duty overrules her preferred way of showing her identity, and when she feels a need to represent "many people" it is due to her fear that they will otherwise be marginalized. She feels that this is a price worth paying - at least she is willing to pay it. This may be seen as a demonstration of strength. Indeed the interviewees, due to the selection criteria, could be characterized as belonging to a "floating zone of elite subalternity" (Spivak in Landry \& MacLean 1996), indicating that they are subject to othering of sorts, but constitute groups of others in important positions equipped with media skills and thus in a position to tackle media marginalization.

\section{Strategic Essentialism?}

One of these skills seems to be to provide journalists with "other others". Robert has experienced being called by one reporter who wanted to do a series on minority youth to show a positive image. He gave them a list with many names, but was called back after a few days for more names. The individuals he had suggested were "too established. I had simply given them a list with a group of youngsters with too 
many resources. [...] They wanted someone who had made it against all odds." The reporter's intention may have been to highlight some role models, presupposing that all minority people are in an 'against-all-odds' situation. In that context, successful people for example "driving a Porsche legally" (Robert) did not meet the requirements, which may be seen as an essentialist interpretation of what it means 'to be a person with minority background'.

This happened some years back. Samira feels that some improvement has taken place, not least because some media companies now have a more diversified journalistic staff:

They are better at normalizing [us] now. [In ] Aften $^{13}$, they are clever at writing quite ordinary articles on Eid, when Eid is there. And not very strange, like 'look how exotic is this party quite apart from our holidays article. Rather straight: Now Eid comes, again [...] it's the result of having clever people with a NorwegianPakistani background in several newsrooms [...] and that they have found many such everyday stories [...]. (Samira)

While Samira voices some optimism, others like Robert are highly critical of presentday journalism, but also demonstrate insight into the reporter's way of thinking, and the pragmatic need to comply with some of the prevailing conventions. One way of exercising this may be to temporarily apply an essentialism of sorts.

Gayatri C. Spivak discusses the experiences of the Subaltern Studies Group, whose aim it is to rewrite the history of India with a perspective from below, deconstructing the imperial version. She reads the work of the Subaltern Studies Group, then, as "a strategic use of positivist essentialism in a scrupulously visible political interest" (Spivak 1985/1996: 214). She compares the application of strategic essentialism to deconstruction by stating that although she uses deconstruction, it does not make her a deconstructivist (Spivak 1990). One may read Spivak as suggesting that the strategic borders on the pragmatic, because, according to her, essentialism has little to do with theory; it rather serves as a definition of a certain political practice.

The very concept of strategic essentialism - which, by the way, even Spivak herself disputes - is a path that has been and continues to be explored as a minority strategy for influencing mainstream society. As I see it, strategic essentialism in this sense entails that members of groups, while being highly differentiated internally, may engage in an essentializing and to some extent a standardizing of their public image, thus advancing their group identity in a simplified, collectivized way to achieve certain objectives. The risk is that, by doing so, they may be playing into the hands of those whose essentialism is more powerful than their own - whether they are researchers, editors, politicians or empire-builders. On the other hand, an increasing public awareness of the risks and strategies involved may help to minimize the risk and maximize the results. The problem occurs when the practice of strategic essentialism is not the result of a deliberate choice and an assessment of a delicate balance, but rather is partly the result of media conventionalism that requires people and groups to essentialize themselves in order to highlight issues that have nothing to do with their daily ontology of being Norwegian and/or a minority within. In other words, the general social situation as well as prevailing media routines may invite a non-preferred practice of making oneself "less Norwegian". But what is this Norwegian-ness? As one interviewee states: 
Many immigrants react against not being represented as one hundred per cent Norwegian. What is Norwegian-ness, Norwegian? [...] That Norwegian-ness is being enlarged and that we represent a new way of being Norwegian is a healthy issue. [There is] no reason to feel insulted by the fact that our ethnic or linguistic background is made visible. I'm proud of belonging to two worlds, but feel very Norwegian, maybe not in the same way as you... (Isabelle)

The question - "What is this Norwegian-ness?" - which implies the importance of nationhood in an era when more and more people may engage in alternative belongings, still seems to prevail in media representation, and thus, strategic adaptation or opposition to this imagined belonging will remain a challenge.

\section{Notes}

1. This article was written by me, Elisabeth Eide, and I also initiated and led the project. Research assistant Vibeke Hoem has done the majority of the interviews, for which I am very thankful. My thanks also are extended to research assistant Egil G. Skogseth, who has done some interviews (4), as I have (3).

2. The interviewees were selected after consultation with a reference group, and after a scrutiny of Retriever (Atekst), the main newspaper article base in Norway. Only individuals with a considerable amount of media exposure were selected. Other individuals with a minority background are included in the larger project as well, for example gay people and people with disabilities. Specifying further the characteristics of the individual informants, such as their social class, occupation, history of migration etc., would infringe on their anonymity.

3. When nothing is specified, all translations of citations - including those of the informants, are our own.

4. All names of the interviewees are fictitious.

5. KRL is a notion for one of the subjects taught at school; it combines the Christian religion with some teachings of other religions and world views. This is now compulsory, while previously the students (or parents) could select a more secular-oriented subject to replace teachings of Lutheranism. This change generated strong reactions both from humanist-ethical agnostics and from religious minorities, Muslims in particular.

6. This is of course also ambiguous, as the feminist claim that "the personal is political" has helped to highlight family abuse, forced marriage and female genital mutilation.

7. Lexically defined as a process through which one is exposed to or subject to the influence of culture.

8. Gullestad also mentions other concepts: neo-racism, cultural differentialism and racist expressions, which many find controversial, and concludes that the critical debate requires much greater efforts towards developing a more analytical and sophisticated understanding (ibid.).

9. Country/nationality omitted due to concerns for informant anonymity.

10. Last year, the (first ever) female leader of the Norwegian Trade Union Council (LO) resigned after critique of her style of leadership - critique that was followed by a massive media campaign against her.

11. Nationality omitted.

12. Researchers within this field of media research may also feel that the media want them to jump to conclusions and not express all their reservations.

13. The evening version of Aftenposten, Norway's largest subscription paper.

\section{References}

Ansari, A. and N.A. Qureshi (1998) Kolleger eller alibier. En studie av politikere med minoritetsbakgrunn. [Colleagues or Alibis: A Study of Politicians with Minority Background] Oslo: HiO-rapport nr 7.

Benson, R. \& E. Neveu (eds.) (2005) Bourdieu and the Journalistic Field. Cambridge: Polity Press.

Bhabha, H. (1990) Nation and Narration. London/NYC: Routledge.

Bourdieu, P. (1998) Om fjernsynet. [On Television.] Oslo: Gyldendal.

Curran, J. (2005) Media and Power. London: Routledge.

Eide E. (2002) "Down here” and "up here” "Europe's Others in Norwegian Feature Stories.Oslo. Doctoral dissertation. Oslo: Unipub. Oslo: HiO rapport $\mathrm{nr} 31$.

Eide, E. \& A.H. Simonsen (2007) Mistenkelige utlendinger. Minoriteter i norsk presse gjennom hundre år. Kristiansand: Høyskoleforlaget. 
Entman, R. (1993) 'Framing: toward Clarification of a Fractured Paradigm', Journal of Communication 43 (4). Oxford: Blackwell.

Eriksen, T.H. (2005) "How can the global be local? Islam, the West and the Globalization of Identity Politics". Pp. 25-41 in Oscar Hemer and Thomas Tufte (eds.) Media and Global Change. Rethinking Communication for Development. Göteborg: Nordicom.

Eriksen, T.H. (2008) Globalization. The Key Concepts. Oxford: Berg.

Fjeldstad, Ø. \& M. Lindstad (2005) Av utenlandsk opprinnelse. Nye nordmenn i avisspaltene. [Of Foreign Origin. New Norwegians Represented in the Newspapers.] Kristiansand: IJ-forlaget.

Friedman, J. (1998) 'Transnationalization, Socio-Political Disorder and Ethnification as Expressions of Declining Global Hegemony', International Political Science Review, Vol. 19, No. 3, 233-250.

Friedman, J. (2005) 'Diasporization, Globalization, and Cosmopolitan Discourse', pp. 140-165 in André Levy \& Alex Weingrod (eds) Homeland and Diasporas: Holy Lands and Other Places. Stanford: Stanford University Press.

Gabriel, J. (2000) 'Dreaming of a White ...', pp. 67-83 in S. Cottle (ed.): Ethnic Minorities and the Media. Maidenhead, Berkshire: Open University Press.

Gans, H.J. (1979) Deciding What's News: A Study of CBS Evening News, NBC Nightly News, Newsweek and Time. New York: Pantheon.

Georgiou, M. (2006) Diaspora, Identity and the Media: Diasporic Transnationalism and Mediated Spatialities. Creskill, NJ: Hampton Press.

Georgiou, M. (2006) Diaspora, Identity and the Media: Diasporic transnationalism and mediated spatialities. Cresskill, NJ: Hampton Press.

Gullestad, M. (2002) Det norske sett med andre øyne. [The Norwegian Seen through Other Eyes] Oslo: Universitetsforlaget.

Landry, D. \& G. MacLean (1996) The Spivak Reade., London: Routledge.

Löffelholz, M. \& D. Weaver (eds.) (2008): Global Journalism Research: Theories, Methods,Findings, Future. Oxford: Blackwell.

Maalouf, A. (2000) On Identity. London: The Harvill Press.

Machin, D. \& T. van Leeuwen (2007) Global Media Discourse. London: Routledge.

Malik, K. (1996) The Meaning of Race. Race, History and Culture in Western Society. London: Macmillan.

Malik, K. (2002) “Against Multiculturalism”, New Humanist, Vol. 117, Issue 2:pp?. (http://newhumanist. org.uk/523). London: The Rationalist Association.

N'Jie, H. (2005) White Lies. (CD) Oslo: Via Music.

Rydin, I. \& U. Sjöberg (eds.) (2008) Mediated Crossroads. Identity, Youth Culture and Ethnicity. Göteborg: Nordicom

Sanders, M. (2006) Gayatri Chakravorty Spivak: Live Theory. London/NYC: Continuum.

Spivak, G.C. (1996 [1985]) "Subaltern Studies. Deconstructing Historiography”, pp.? in D. Landry \& G. MacLean (1996) The Spivak Reader. London: Routledge.

Spivak, G.C (Sarah Harasym, ed.) (1990) The Post-colonial Critic. NY: Routledge.

Storm-Mathisen, A. \& J. Helle-Valle (2008) "Media, Identity and Methodology. Reflections on Practice and Discourse", in Rydin \& Sjöberg, op.cit.

ELISABETH EIDE, Ph.D., Associate Professor, Faculty of Journalism, Library and Information Science, Oslo University College, elisabeth.eide@jbi.hio.no 